\title{
A case of impaction of an ingested foreign body in the appendix
}

\author{
Sandeep Hambarde ${ }^{1}$, Ashwini Gadekar ${ }^{2}$ \\ Sri Lanka Journal of Child Health, 2012; 41(3): 145
}

(Key words: Impaction, foreign body, appendix)

\section{Case report}

An 11 month old boy was admitted with a history of accidental ingestion of a foreign body (FB). X-ray of the abdomen showed an open safety pin in the right lower quadrant. Serial radiographs showed a fixed position in the right lower abdomen.

In view of the fixed position of the sharp object on serial x-rays, exploratory laparotomy was done. The appendix was opened longitudinally away from base, the safety pin was retrieved and formal appendicectomy was completed. The postoperative course was uneventful.

\section{Discussion}

FBs in the appendix are uncommon, one study showing a frequency of $0.005 \%$ in 13,228 patients ${ }^{1}$. Usually ingested FBs pass through the alimentary tract spontaneously ${ }^{2}$. Sometimes, ingested FBs may remain dormant within an appendix for extended periods without inciting an inflammatory response ${ }^{3}$. However, cases of FB-induced appendicitis have been documented ${ }^{4}$. Sharp and pointed objects are more likely to cause perforations and abscesses ${ }^{5}$. However, reported incidence of bowel perforation is less than $1 \% 5$. When a FB becomes incarcerated in appendix, even if asymptomatic, a prophylactic appendicectomy is recommended to prevent appendicitis ${ }^{6}$.

Needles $^{7}$, metallic screw ${ }^{8}$ and hazel nut ${ }^{9}$ have been reported to be causes of FB appendicitis in children. In a series of 217 cases of appendiceal FBs reviewed by Balch and Silver, pins were found to be the most common ${ }^{1}$. In our patient, an open safety pin was impacted in the appendix and a prophylactic appendicectomy done during exploratory laparotomy.

\footnotetext{
${ }^{1}$ Senior Resident, Department of Paediatric Surgery, BJWHC, ${ }^{2}$ Associate Professor, Department of Obstetrics and Gynecology, KEM Hospital, Mumbai, India
}

(Received on 29 July 2011: Accepted after revision on 9 December 2011)

\section{References}

1. Balch CM, Silver D. Foreign bodies in the appendix: report of eight cases and review of the literature. Archives of Surgery 1971; 102:14-20. http://dx.doi.org/10.1001/archsurg.1971.0135001 $\underline{0016004}$

2. Selivanov V, Sheldon GF, Cello JP, et al. Management of foreign body ingestion. Annals of Surgery 1984; 199: 187-91. http://dx.doi.org/10.1097/00000658-19840200000010

3. Reddy ER. Retained lead shot in the appendix. Journal Canadian Association of Radiologists 1985; 36:47-8.

4. Sukhotnik I, Klin B, Siplovich L. Foreign body appendicitis. Journal of Pediatric Surgery 1995; 30: $1515-6$.

http://dx.doi.org/10.1016/0022-3468(95)90427-1

5. Klingler PJ, Seelig MH, DeVault KR, et al. Ingested foreign bodies within the appendix: a 100-year review of the literature. Digestive Diseases 1998; 16:308-14. http://dx.doi.org/10.1159/000016880

6. Bertozzi M, Nardi N, Falcone F, Prestipino M, Appignani A. An unusual case of asymptomatic appendicular cutting foreign body. Pediatria Medica e Chirurgica 2010; 32(5):223-5.

7. Sinha DD, Sharma C, Gupta V, Chaturvedi V. Sewing needle appendicitis in a child. Indian Journal of Gastroenterology 2004; 23:219-20.

8. Kumar R, Bawa M, Raghawan M. Ingested metallic screw causing appendicitis in an infant. Indian Journal of Pediatrics 2010; 77:337. http://dx.doi.org/10.1007/s12098-009-0295-7

9. Kucukaydin M, Icer M, Okur H. Hazelnut appendicitis. Pediatric Surgery International 1992; 7:223-4. http://dx.doi.org/10.1007/BF00175848 